\title{
The impact of regional income inequality on residents' health in China
}

\author{
Zixiao Jiang ${ }^{1,}$ a , Zhongyi Feng, b \\ ${ }^{1}$ School of Humanities, Social Sciences \& Law, Harbin Institute of Technology, Heilongjiang, China \\ ${ }^{2}$ School of Economics and Finance, Xi'an Jiaotong University, Xi'an, China
}

\begin{abstract}
Since the reform and opening up, China's economy has been developing, residents' income has been increasing, people's health awareness has also been building up, and the health situation has gradually improved. However, with the development of Chinese economy, the problem of income inequality also follows, which has an impact on the health of Chinese residents. In particular, the imbalance of regional economic development and the difference between urban and rural residents' disposable income inequality have a negative impact on the health of residents, which is not conducive to sustainable economic development and social harmony and stability. This paper analyzes the correlation between regional income inequality and residents' health status, uses descriptive statistical analysis and principal component analysis to do empirical analysis on the relationship between regional income inequality and residents' health status, and selects the data from "China Health Statistics Yearbook 2019". The results of empirical analysis show that regional income inequality has an impact on the health of residents in China. The health level of residents in high-income areas is higher than that in low-income areas. The economic development of the eastern and northern regions is better than that of the central and western regions, and the health status of the residents in the eastern and northern regions is better than that in the central and western regions. In addition, urban-rural income inequality also has an impact on the health of residents. The data show that the health status of urban residents is better than that of rural residents. It can be seen that there is a positive correlation between income level and residents' health level, and a negative correlation between income inequality and residents' health level. That is, the higher the income, the higher the health level of residents, the lower the income, the lower the health level of residents; the higher the degree of income inequality, the worse the health status of residents, and it is not conducive to the overall improvement of the health level of residents.
\end{abstract}

\section{INTRODUCTION}

With the development of the China's economy, people's income continues to increase, at the same time, the social attention to the health of residents is also increasing. Health not only affects individuals, but also has a close relationship with the development of society. (Strauss, 1998). So, paying attention to residents' health and narrowing the health gap between urban and rural residents is conducive to promoting labor force and living quality, improving social productivity, and enhancing economic development and social harmony.

In the international community, the health of residents is one of the important indicators to judge the progress of a country's civilization and society development. Both the World Health Organization and the United Nations have identified health level as an important dimension of social development. From the economic perspective, health is a part of human capital (Bleakley, 2010). Health directly affects the input of basic factors of production, and then promotes economic development (Grossman, 2000). Good health means more input of basic production factors, which leads to higher economic output and higher income level. The improvement of income level will promote the improvement of health status, which is a kind of positive feedback and conducive to the sustainable development of China's economy and society.

At the time of Fifth Plenary Session of the 18th CPC Central Committee, building a "healthy China" has become a national strategy (Guo, 2016). The promotion of health can not only directly create productive forces, but also closely interact with economic development. The concept of health development will become increasingly popular among people and gradually integrate into the governing philosophy of Chinese government. The government's health investment and residents' medical security will be further increased. For the society long-term development, ensuring people's health is not only an important way to increase people's happiness, but also interacting with economic development. 
Since the reform and opening up, China's economy has been developing continuously, and the Gini coefficient has also been rising day by day (Cheng, 2007). The Gini coefficient is a comprehensive indicator reflecting the degree of income gap among residents. In the international community, 0.4 is usually used as the warning line for the Gini coefficient. China's Gini coefficient at the end of 2019 is $0.465 \mathrm{NA}$, indicating that China has a large income gap and face the problem of income inequality.

There is a close relationship between income and health (H Li, 2008). As China's economy has grown, people's health have risen, but the gap between urban and rural health care spending remains huge. In addition, the average life expectancy of citizens has been rising, while the neonatal and infant mortality rates have been falling. Data show that the neonatal mortality rate and infant mortality rate in urban China are much lower than that in rural areas. It can be seen that income gap is an influencing factor affecting the health of residents. This paper will analyze how regional income inequality affects the health of urban and rural residents, and explore the relationship between them.

\section{DATA COLLECTION AND METRICS}

\subsection{Data Collection}

The data collected in this paper are mainly from "China Health Statistics Yearbook 2019”, which published by Chinese National Health Commission. It provides statistical data on the health level of residents in total provinces, autonomous regions and municipalities directly controlled by the central government. Data collected in the paper cover a total of 31 provinces in China, reflecting residents' income in different regions of China and the impact of income inequality on the residents' health status.

\subsection{Metrics}

According to the scientific and operational principles of collecting data, metrics are selected from the aspects affecting the health of residents. 8 specific indicators are selected to analyze the health level of residents in all regions of the country, as shown in the table below:

Table 1 The health level index system of urban and rural residents in all regions in China

\begin{tabular}{|c|}
\hline $\mathrm{X}_{1}$ : Per capita disposable income (Yuan) \\
\hline $\mathrm{X}_{2}$ : Per capita health care expenditure (Yuan) \\
\hline $\mathrm{X}_{3}:$ Total health costs per capita (Yuan ) \\
\hline $\mathrm{X}_{4}:$ Number of medical and health institutions \\
\hline $\mathrm{X}_{5}:$ Birth rate $(\%)$ \\
\hline $\mathrm{X}_{6}:$ Mortality rate $(\%)$ \\
\hline $\mathrm{X}_{7}$ : Natural population growth rate $(\%)$ \\
\hline $\mathrm{X}_{8}:$ Life expectancy $($ Year $)$ \\
\hline
\end{tabular}

\subsection{Statistical significance of indicators}

$\mathrm{X}_{1}$ : Per capita disposable income (Yuan) :

The part of the household's total cash income that can be used to arrange the family's daily life in a certain period of time

$\mathrm{X}_{2}$ : Per capita health care expenditure (Yuan)

Refers to all expenditures of residents in part of medical and health care in a certain period of time, reflecting the residents' personal attention to medical care and the level of cost burden.

$\mathrm{X}_{3}$ : Total health costs per capita (Yuan)

Refers to the total expenditure of individuals for various medical and health services in a certain period of time

$\mathrm{X}_{4}$ : Number of medical and health institutions

Refers to the number of units that have obtained the "Medical Institution Practicing License" from the health administrative department; or pass the registration certificate of legal entity to provide the society with medical care, disease control, health supervision services; or engaged in medical research and medical on-the-job training. Medical and health institutions include hospitals; primary medical and health institutions; professional public health institutions; and other medical and health institutions.

$\mathrm{X}_{5}$ : Birth rate $(\%)$

The number of births in a certain region during the year

The average number of people in the same period

The number of births: The number of live births

The annual average number: The average number of populations at the beginning and end of the year, which can also be replaced by the number of mid-year populations.

$\mathrm{X}_{6}$ : Mortality rate $(\%)$

The number of deaths in a certain region during the year

The average number of people in the same period

$\mathrm{X}_{7}$ : Natural population growth rate $(\%)$

The natural population increase in a certain area during the year The average number of people in the same period

Or

Birth rate of each area -Death rate of the population in each area

$\mathrm{X}_{8}$ : Life expectancy

The average number of years that a new born baby can expect to live in a certain region and year. It is also called life expectancy at birth. The average life expectancy is generally expressed in years.

\section{METHODOLOGY}

\subsection{Descriptive statistical analysis}

\subsubsection{Urban and rural income inequality between regions}

Figure 1 shows the ratio of urban per capita disposable income to rural per capita disposable income in 31 provinces and municipalities in 2017. The larger the 
urban-rural disposable income ratio, the larger the per capita income gap between urban and rural areas, and the more serious urban-rural income inequality. It can be seen from the figure that the national average income ratio is 2.68 , some provinces are higher than the average, and some provinces are lower than the average.

The urban-rural per capita disposable income ratio in Gansu, Guizhou, and Yunnan is much higher than the national average ratio, and the highest in Gansu is 3.4, indicating that the income gap between urban and rural residents in these provinces is large. In addition, the figure shows that the ratio in Tianjin, Zhejiang, and Heilongjiang are relatively low, and the income gap between residents is small. The eastern and northern provinces of the remaining provinces are close to or slightly lower than the national average, and the central and western provinces are close to or slightly higher than the national average. Therefore, there are some differences between regional and urban-rural income distribution in China.

\section{Urban-rural disposable income ratio}

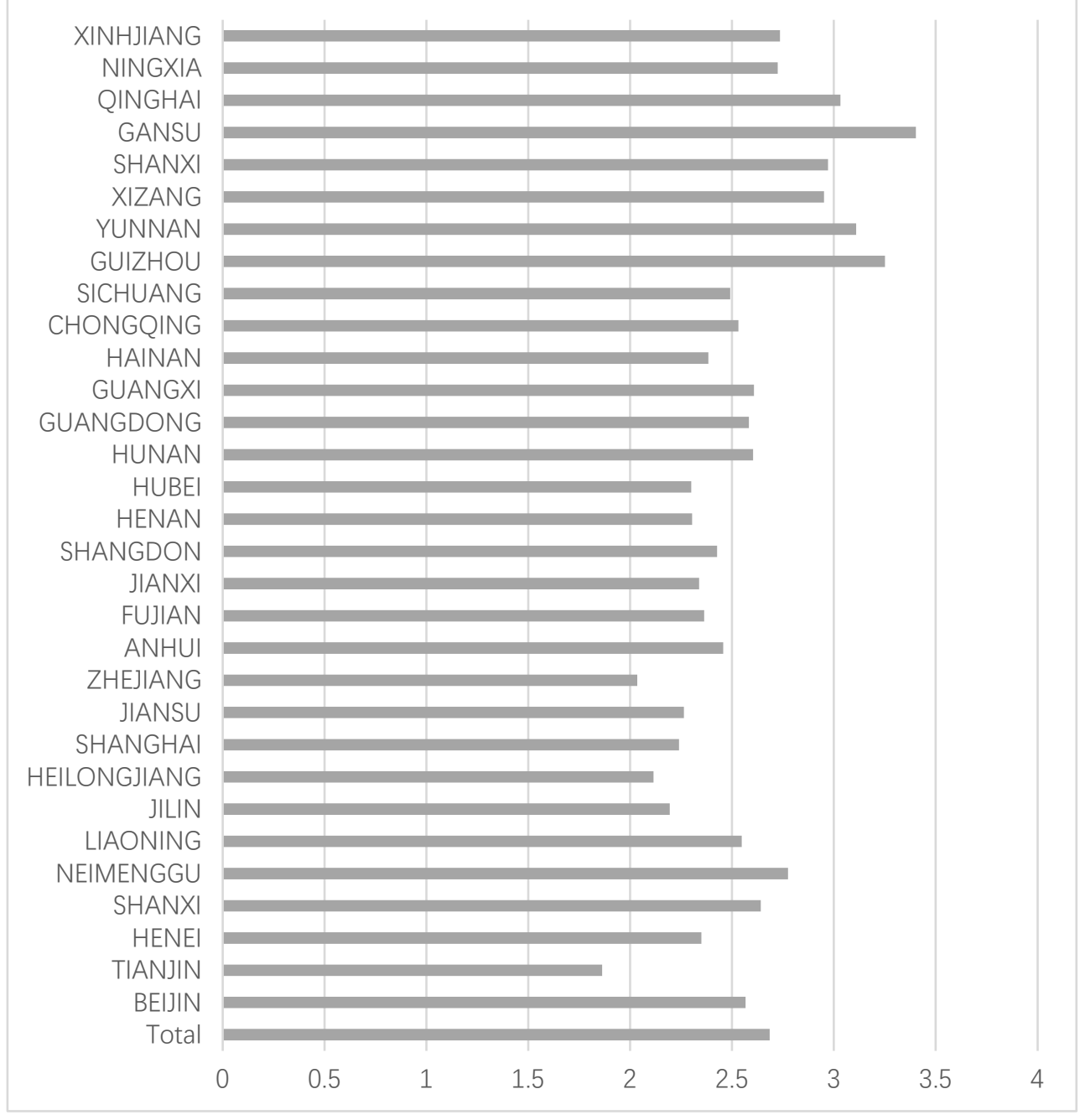

Figure 1 Per capita disposable income ratio of 31 provinces, municipalities, cities and rural areas; 2017

\subsubsection{Urban and rural health care expenditure between regions}

Figure 2 shows the ratio of urban per capita healthcare expenditure to rural per capita healthcare expenditure in 31 provinces and municipalities in 2017. The larger the urban-rural health care expenditure ratio, the greater the gap between urban and rural health care expenditures, and the greater the gap between urban and rural medical resources and health levels. It can be seen from the figure that the national average expenditure ratio is 1.65 . Some provinces are higher than the average, and some provinces are lower than the average. Among them, the urban-rural per capita health care expenditure ratio in Tibet, Yunnan, and Hainan is much higher than the national average. The highest rate in Tibet is 4.33. Much lower than the city. In addition, the figure also shows that the per capita health care expenditure in Jiangsu, Heilongjiang, and Anhui is lower than the relative average level, indicating that the urban-rural gap is small. The rest of the provinces are closer to the average. The eastern and northern provinces are slightly lower than the national average, and the central and western provinces are slightly higher than the national average. It can be 
seen that in terms of health care expenditures, China also has regional gaps and urban-rural gaps.

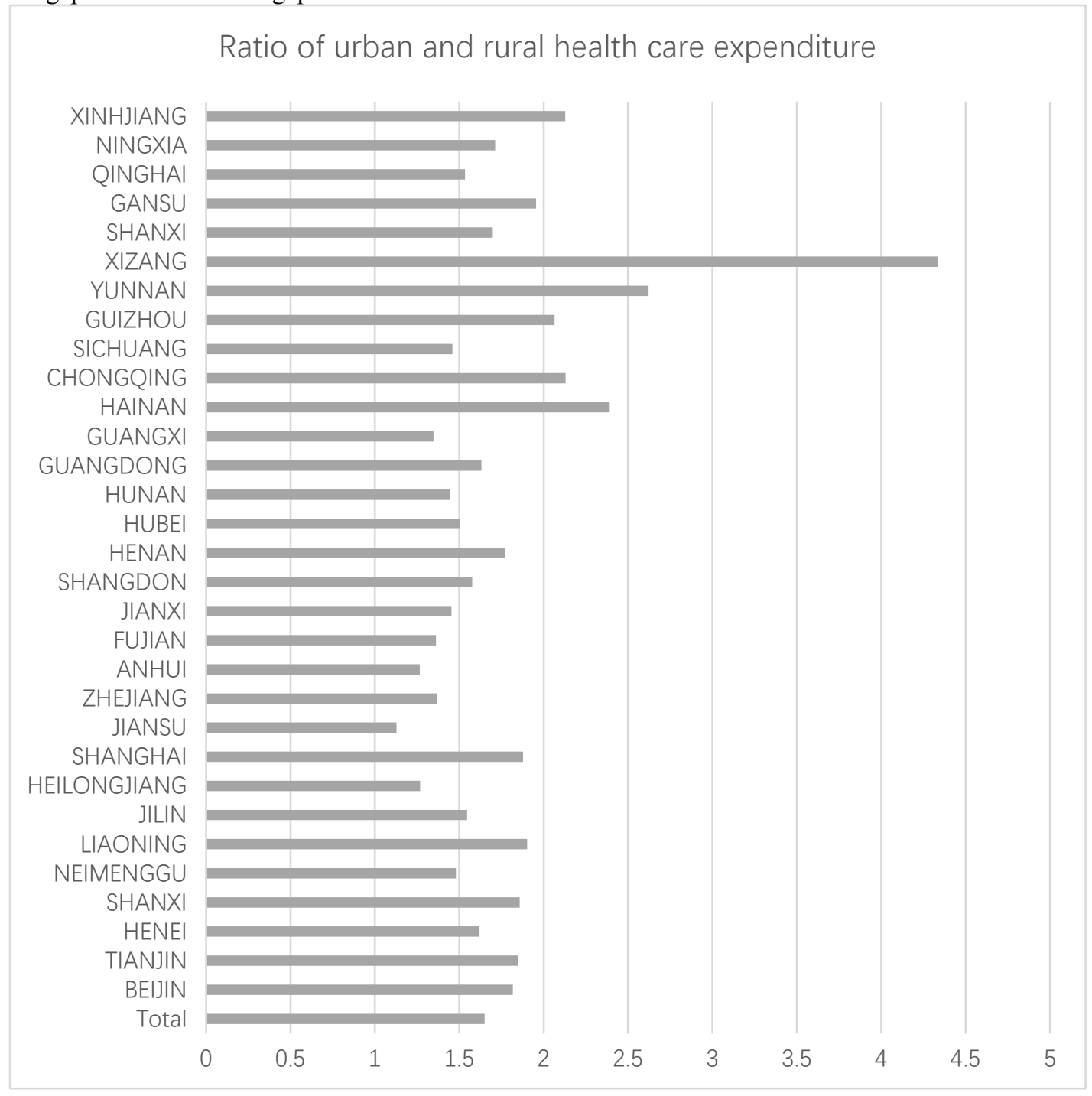

Figure 2: The ratio of per capita health care expenditures in 31 provinces, municipalities, cities and rural areas; 2017

\subsection{Principle component analysis method}

In the aspect of empirical analysis, this paper mainly uses SPSS software and principal component analysis method to analyze the relationship between income inequality and the health of Chinese residents. This paper selects a total of eight indicators to reflect the residents' health level. Each indicator in the index system has different form to reflect the perspective of residents' health level, so it is hard to avoid certain correlation between each other and stop overlapping information on impact assessment. In order to better use of these indicators to character comprehensive residents health level, this article uses principal component analysis to analyze the main indicators to measure the influence of the residents' health level in different areas.

\subsubsection{Coefficient of correlation}

Table 2 below is the correlation coefficient matrix of the 8 variables. It can be concluded from Table 2 that the correlation between the variables is high, which can be used for principal component analysis.

\section{Table 2}

\section{Correlation matrix}

\begin{tabular}{|c|c|c|c|c|c|c|c|c|c|}
\hline & & $\mathrm{x} 1$ & $\mathrm{x} 2$ & $\mathrm{x} 3$ & $\mathrm{x} 4$ & $\mathrm{x} 5$ & $\mathrm{x} 6$ & $\mathrm{x} 7$ & $\mathrm{x} 8$ \\
\hline \multirow[t]{3}{*}{ Correlation } & $\mathrm{x} 1$ & 1.000 & .739 & .877 & -.021 & -.403 & -.293 & -.303 & .778 \\
\hline & $\mathrm{x} 2$ & .739 & 1.000 & .754 & -.209 & -.687 & -.127 & -.616 & .726 \\
\hline & $\mathrm{x} 3$ & .877 & .754 & 1.000 & -.436 & -.370 & -.428 & -.235 & .548 \\
\hline
\end{tabular}




\begin{tabular}{lrrrrrrrrr}
\hline $\mathrm{x} 4$ & -.021 & -.209 & -.436 & 1.000 & .211 & .504 & .064 & .049 \\
\hline $\mathrm{x} 5$ & -.403 & -.687 & -.370 & .211 & 1.000 & -.059 & .963 & -.527 \\
\hline $\mathrm{x} 6$ & -.293 & -.127 & -.428 & .504 & -.059 & 1.000 & -.325 & -.058 \\
\hline $\mathrm{x} 7$ & -.303 & -.616 & -.235 & .064 & .963 & -.325 & 1.000 & -.484 \\
\hline $\mathrm{x} 8$ & .778 & .726 & .548 & .049 & -.527 & -.058 & -.484 & 1.000 \\
\hline
\end{tabular}

\subsubsection{Total variance explanation table}

Table 3 shows how each principal component explains cumulative contribution rate of the first three principal components is as high as $88.808 \%$, three principal components are selected to reduce the eight-dimensional the total variance of the original variables. Since the problem to the three-dimensional problem.

Table 3

\section{Total Variance Explained}

\begin{tabular}{|c|c|c|c|c|c|c|}
\hline \multirow[b]{2}{*}{ Component } & \multicolumn{3}{|c|}{ Initial Eigenvalues } & \multicolumn{3}{|c|}{ Extraction Sums of Squared Loadings } \\
\hline & Total & $\%$ of Variance & Cumulative $\%$ & Total & $\%$ of Variance & Cumulative \% \\
\hline 1 & 4.122 & 51.523 & 51.523 & 4.122 & 51.523 & 51.523 \\
\hline 2 & 1.913 & 23.913 & 75.436 & 1.913 & 23.913 & 75.436 \\
\hline 3 & 1.070 & 13.371 & 88.808 & 1.070 & 13.371 & 88.808 \\
\hline 4 & .420 & 5.253 & 94.060 & & & \\
\hline 5 & .261 & 3.263 & 97.323 & & & \\
\hline 6 & .172 & 2.145 & 99.468 & & & \\
\hline 7 & .043 & .532 & 100.000 & & & \\
\hline 8 & $8.084 \mathrm{E}-16$ & $1.010 \mathrm{E}-14$ & 100.000 & & & \\
\hline
\end{tabular}

\subsubsection{Principal component analysis-Scree Plot}

Figure 3 is a principal component analysis-Scree Plot. The abscissa represents the number of components, and the ordinate represents the characteristic value. It can be seen that the characteristic value of the fourth principal component is obviously less than 1, which again confirms the conclusion that the three principal components are extracted from the total variance interpretation.

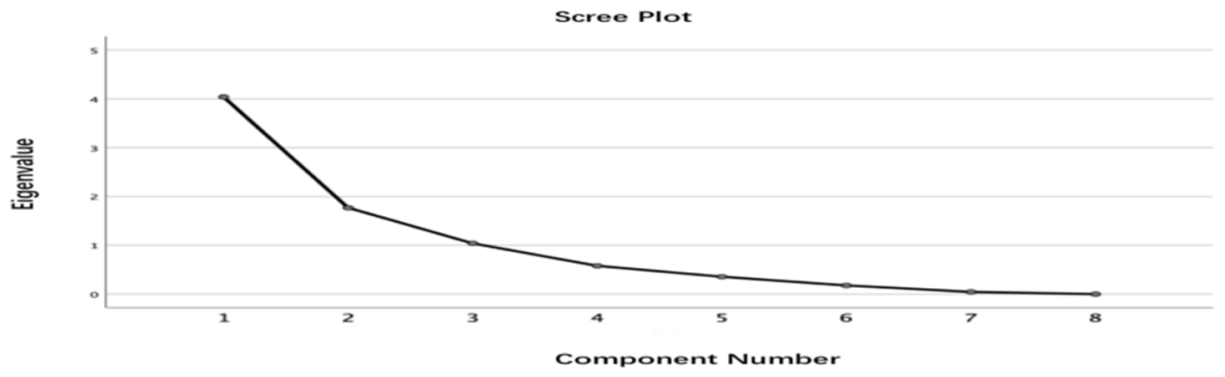

Figure 3 Principal component analysis Scree Plot

\subsubsection{Principal component coefficient matrix}

Table 4 is the principal component coefficient matrix, which explains the load of each principal component on each variable. From this, the expression of the three principal components is obtained. In the expression, each variable is no longer original, but standardized.
$\mathrm{Y}_{1}=$

$0.858 Z x 1+0.923 Z \times 2+0.823 Z \times 3-0.322 Z x 4-0.774 Z \times 5-0.2$

$13 Z \times 6-0.676 Z \times 7+0.807 Z x 8$

$\mathrm{Y}_{2}=$

$0.249 Z \times 1-0.060 Z \times 2+0.435 Z \times 3-0.578 Z \times 4+0.435 Z \times 5-0.8$

$41 \mathrm{Zx} 6+0.638 \mathrm{Z} \times 7-0.141 \mathrm{Zx} 8$ 
$\mathrm{Y}_{3}=$

$0.359 \mathrm{Zx} 1+0.058 \mathrm{Z} \times 2+0.123 \mathrm{Zx} 3+0.668 \mathrm{Zx} 4+0.408 \mathrm{Z} \times 5+0$.

$117 \mathrm{Zx} 6+0.355 \mathrm{Zx} 7+0.412 \mathrm{Zx} 8$
Total score calculation formula: $\quad \mathrm{F}=0.515 \mathrm{Y}_{1}+$ $0.239 \mathrm{Y}_{2}+0.134 \mathrm{Y}_{3}$

Table 4

\section{Component Matrix}

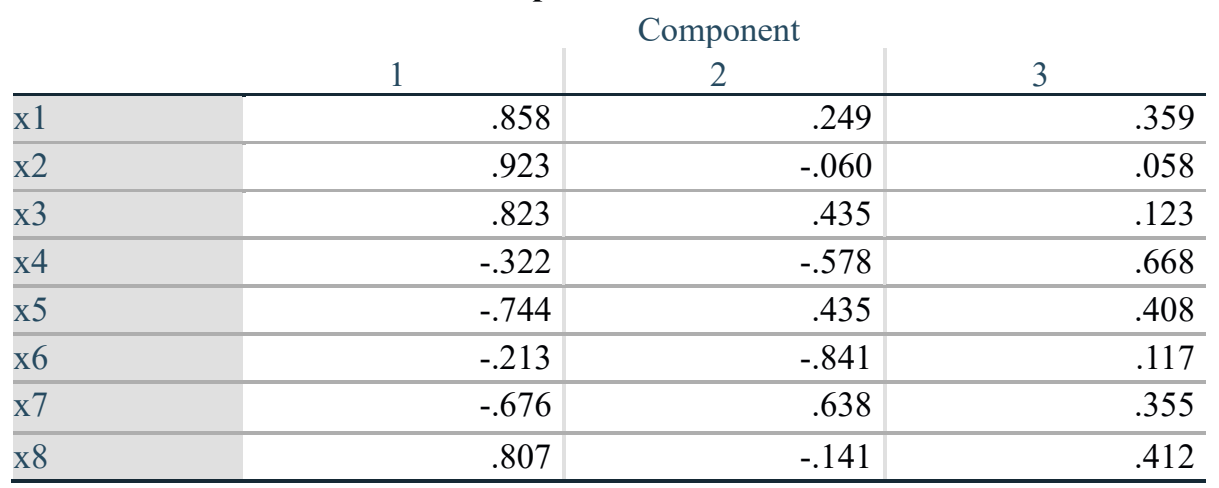

in different regions of my country. After using SPSS to

\section{RESULT}

The economic development of China's 31 provinces and municipalities is uneven, and income levels are also different, which has an impact on the health of residents analyze the original data, the comprehensive scores of 31 provinces and municipalities across the country are shown in the following table:

Table 5 Principal component comprehensive scores and rankings of 31 provinces and municipalities

\begin{tabular}{|c|c|c|c|c|c|c|c|c|}
\hline Area & $\mathrm{y} 1$ & Rank & $\mathrm{y} 2$ & Rank & y3 & Rank & score & Rank \\
\hline BEIJING & 11.56 & 1 & 2.47 & 4 & 1.06 & 4 & 6.68 & 1 \\
\hline TIANJIN & 6.93 & 3 & 0.76 & 12 & -0.75 & 22 & 3.65 & 3 \\
\hline HEBEI & -2.38 & 22 & -1.91 & 26 & 1.58 & 2 & -1.47 & 24 \\
\hline SHANXI & -0.9 & 15 & -0.22 & 16 & -0.29 & 18 & -0.55 & 18 \\
\hline NEIMENGGU & 1.51 & 9 & -0.26 & 17 & -0.95 & 25 & 0.59 & 9.5 \\
\hline LIAONING & 3.84 & 4 & -3.22 & 31 & -0.98 & 26 & 1.08 & 5 \\
\hline JILIN & 3.03 & 7 & -2.38 & 28 & -1.58 & 30 & 0.78 & 7 \\
\hline HEILONGJIANG & 3.12 & 5 & -2.7 & 29 & -1.83 & 31 & 0.72 & 8 \\
\hline SHANGHAI & 10.94 & 2 & 1.91 & 6 & 0.6 & 10 & 6.17 & 2 \\
\hline JIANGSU & 2.65 & 8 & -1.66 & 25 & 0.06 & 14 & 0.98 & 6 \\
\hline ZHEJIANG & 3.1 & 6 & 1.08 & 9 & 1.02 & 5 & 1.99 & 4 \\
\hline ANHUI & -2.33 & 21 & 0.77 & 11 & 0.03 & 15 & -1.01 & 20 \\
\hline FUJIAN & -1.66 & 18 & 1.02 & 10 & 0.78 & 9 & -0.51 & 17 \\
\hline SHANXI & -3.14 & 27 & 0.19 & 14 & 0.15 & 13 & -1.55 & 26 \\
\hline SHANDONG & -3.06 & 26 & -1.05 & 21 & 3.05 & 1 & -1.42 & 23 \\
\hline HENAN & -2.65 & 24 & -2.1 & 27 & 1 & 6 & -1.73 & 28 \\
\hline HUBEI & -0.08 & 12 & -1.17 & 22 & 0.2 & 12 & -0.3 & 14 \\
\hline HUNAN & -1.81 & 19 & -1.63 & 24 & 0.81 & 8 & -1.22 & 22 \\
\hline GUANGDONG & -0.19 & 13 & 2.13 & 5 & 1.37 & 3 & 0.59 & 9.5 \\
\hline GUANGXI & -3.29 & 28 & 0.48 & 13 & 0.48 & 11 & -1.51 & 25 \\
\hline HAINAN & -1.46 & 17 & 1.62 & 7.5 & -0.09 & 17 & -0.38 & 15 \\
\hline CHONGQING & 0.51 & 10 & -1.53 & 23 & -0.5 & 20 & -0.17 & 13 \\
\hline SICHUAN & -1.3 & 16 & -2.81 & 30 & 0.99 & 7 & -1.21 & 21 \\
\hline GUIZHOU & -4.45 & 30 & -0.39 & 18 & -0.67 & 21 & -2.48 & 30 \\
\hline YUNNAN & -3.91 & 29 & -0.08 & 15 & -1.01 & 27 & -2.17 & 29 \\
\hline
\end{tabular}




\begin{tabular}{lrrrrrrrr} 
XIZANG & -6.4 & 31 & 3.69 & 2 & -1.28 & 29 & -2.58 & 31 \\
SHANXI & 0.29 & 11 & -0.7 & 20 & -0.35 & 19 & -0.07 & 12 \\
GANSU & -2.71 & 25 & -0.53 & 19 & -0.85 & 23 & -1.64 & 27 \\
& & & & & & & & \\
QINGHAI & -2.32 & 20 & 1.62 & 7.5 & -1.1 & 28 & -0.96 & 19 \\
NIGXIA & -0.8 & 14 & 2.86 & 3 & -0.89 & 24 & 0.15 & 11 \\
XINJIANG & -2.63 & 23 & 3.75 & 1 & -0.07 & 16 & -0.47 & 16 \\
\hline
\end{tabular}

According to the comprehensive scores in the above table, the top five regions are Beijing, Shanghai, Tianjin, Zhejiang, and Liaoning; the bottom five regions are Gansu, Henan, Yunnan, Guizhou, and Tibet. This is basically in line with China's economic development: the eastern and northern regions have better economic development than the central and western regions, the eastern and northern regions have relatively higher per capita disposable incomes, and the central and western regions have lower per capita disposable incomes. Therefore, the income level is positively correlated with the residents' health level, that is, the increase in the income level will promote the improvement of the residents' health status.

The top-ranked provinces and cities have higher per capita disposable income, as well as higher health care expenditures and total health expenditures. Higher per capita disposable income provides financial support for the medical care of residents in these areas. The higher the income level, the better medical resources available to residents. When the residents' health status declines, numerous medical and health institutions and better medical standards provide external support for their recovery, and their high income provides them with financial support for paying high medical expenses. In addition, residents in high-income areas are becoming more aware of their health and spending relatively more on medical care. On the contrary, residents in the central and northern regions have relatively low incomes, fewer medical and health institutions, and relatively backward medical standards, which will lead to the deterioration of residents' health.

In addition, a healthy body is an important support for engaging in production activities. A healthy body helps residents spend more time and energy at work, thereby obtaining more income. High income also promotes the improvement of health status, forming a virtuous circle. Therefore, income inequality not only affects the health of residents in the short term, but also has an increasing impact on the health of residents in the long run. Under the benign and vicious circle of the relationship between income and health, the medical resources enjoyed by high-income residents are getting better and better, while the medical resources enjoyed by low-income residents are declining. The increase in disparity not only directly affects the health of residents, but also leads to aggravation of social conflicts. Therefore, the impact of income inequality on the health of residents is negative.

\section{CONCLUSION AND RECOMMENDATIONS FOR FUTURE RESEARCH}

This paper uses SPSS statistical analysis software to analyze data from the "China Health Statistics Yearbook 2019", creates an indicator system, and analyzes the impact of income inequality on the health of residents by region. Income inequality is manifested in the ever-increasing regional income gap and urban-rural income gap. The inequality of residents' health is reflected in the gaps in regional medical and health institutions, medical care expenditures, natural population growth, and average life expectancy. Income level is positively correlated with residents' health level, and income inequality is negatively correlated with residents' health level. That is, the higher the health level of high-income residents, the lower the health level of low-income residents; the higher the income inequality, the worse the health status of residents. Although the income gap between urban and rural residents has a smaller impact on health, the income inequality between urban and rural residents causes rural residents to have worse health conditions than urban residents. In terms of regional income gaps, the eastern and northern of China have higher incomes and the residents' health status is better; the central and western residents' relative per capita disposable income, medical care expenditures, and total health expenditures are less, and the residents' health status is poor.

Through analyzing the impact of income inequality on the health of residents, policy recommendations can start with increasing residents' income, narrowing the residents' income gap, and improving medical and health conditions to improve the overall health of Chinese residents. First, in order to improve the health of residents, it is necessary to increase income while narrowing the income gap because income is positively correlated with health, and income inequality is negatively correlated with health. Therefore, government need to increase the proportion of residents' income in the distribution of national income and establish a perfect economic system to promote employment and expand wage income. In addition, the government need encourage entrepreneurship to increase income from business operations, promote the reform of income distribution system to establish a more perfect social income distribution system, and strengthen supervision to make good use of tax regulation mechanism. Secondly, the level of regional economic development will also affect the income of residents. The income gap of residents in China is deeply affected by the region. For 
this reason, government can promote the economic development of the central and western regions, and narrow the gap with the east and the north to enhance the overall health of residents. Finally, medical and health protection and health awareness are also important factors affecting the health of residents. Finally, health care security and health awareness are also important factors affecting the health of residents. In order to improve the health level of residents, government can vigorously publicize health knowledge and further strengthen the medical security system. Residents in rural areas and economically underdeveloped areas need to have the awareness of health-care to improve the overall health status of Chinese residents.

\section{REFERENCES}

1. Strauss, J., \& Thomas, D.. (1998). Health, nutrition and economic development. Journal of Economic Literature, 36(2), 766-817.

2. Bleakley, H. Health, human capital, and development. Annu. Rev. Econ. 2010, 2, 283-310.

3. Guo, \& Weihe. (2016). Insights from the fifth plenary session of the 18th cpc central committee on indigenisation of the path of development of social work in china. China Journal of Social Work, 9(1), 92-95.

4. Cheng, Y.H. (2007). China's overall Gini coefficient since reform and its decomposition by rural and urban areas since reform and opening-up. Social Sciences in China, ,45-60+205. doi: CNKI: SUN: ZSHK.0.2007-04-004.

5. Li, H., \& Zhu, Y. (2008). Income, income inequality, and health: evidence from china. Journal of Comparative Economics, 34. 